\title{
A phase II study of chloroquinoxaline sulfonamide (CQS) in patients with metastatic colorectal carcinoma (MCRC)
}

\author{
Tanios S. Bekaii-Saab ${ }^{1,2}$, Amir Mortazavi ${ }^{1}$, Lee G. Hicks ${ }^{3}$, Mark Zalupski ${ }^{4}$, Robert J. Pelley ${ }^{5}$, \\ Kenneth K. Chan ${ }^{6}$ and Eric H. Kraut ${ }^{1}$ \\ ${ }^{1}$ Division of Hematology and Oncology, Department of Medicine, The Ohio State University-James Cancer Hospital, \\ Columbus, OH; ${ }^{2}$ Department of Pharmacology, The Ohio State University; ${ }^{3}$ Central Baptist Hospital, Lexington, KY; \\ ${ }^{4}$ Division of Hematology and Oncology, University of Michigan, Ann Arbor, MI; ${ }^{5}$ Division of Hematology and Oncology, \\ Cleveland Clinic, Cleveland, $\mathrm{OH} ;{ }^{6}$ Colleges of Pharmacy and Medicine and Public Health, The Ohio State University, \\ Columbus, $\mathrm{OH}$
}

Published online: 28 January 2006

Key words: colon cancer, Chloroquinoxaline Sulfonamide, metastatic, investigational drug

\begin{abstract}
Summary
Purpose: Phase II multicenter study investigated the efficacy and toxicity of the novel halogenated derivative of sulfaquixonaline Chloroquinoxaline Sulfonamide (CQS) in metastatic colorectal cancer. Experimental design: Eligible patients with metastatic or recurrent colorectal cancer received CQS at a dose schedule of $2000 \mathrm{mg} / \mathrm{m}^{2}$ over an hour weekly for 4 weeks every 42 days. Treatment was continued until unexpected toxicity or disease progression. Results: A total of seventeen patients were enrolled on this study. $94 \%$ of all patients enrolled had prior treatment. Sixteen patients were evaluable for response with fifteen patients showing evidence of disease progression and one patient with prolonged stable disease. One patient had non-evaluable disease. Following this interim analysis, the drug was considered ineffective and the study was terminated early. The most frequent adverse event was anemia. No patients discontinued the treatment because of toxicity. Conclusion: CQS, when given at a dose of $2000 \mathrm{mg} / \mathrm{m}^{2}$ weekly for 4 weeks every 42 days to patients with metastatic colorectal cancer, does not result in significant tumor regression.
\end{abstract}

\section{Introduction}

Adenocarcinoma of the colon and rectum is a major health problem in the United States with approximately 150,000 cases estimated to occur in the year 2005 [1]. One-third of those patients will die from their disease every year [1]. The overall survival in colorectal cancer is $62 \%$ with only about $8-9 \%$ surviving 5 years with metastatic disease [2]. Chemotherapy has been the mainstay of therapy in patients with metastatic disease with modest effects on survival.

The investigational drug Chloroquinoxaline Sulfonamide (CQS) is a halogenated derivative of sulfaquixonaline, an antifungal agent used in the control of coccidiosis in animals [3]. The mechanism of action of this compound is largely unknown until recently, although unlike sulfaquixonaline, it does not interfere with folate homeostasis [4]. In vitro, CQS acts as a topoisomerases (topo) II $\alpha$ and II $\beta$ poison, thus inhibiting DNA replication [5]. CQS was found to induce arrest of mitogen stimulated lymphocytes in $\mathrm{G}_{0} / \mathrm{G}_{1}$ stage of the cell cycle [5-7]. The antitumor activity of CQS was first discovered in the human tumor colony-forming assay, with inhibitory effects against human lung, colon, breast and other tumor types. In vivo studies of CQS using H82 small cell lung tumor implanted subcutaneously into athymic mice resulted in tumor regression when the drug was given via intraperitoneal and subcutaneous routes for five days [4].

Three phase I studies with CQS were conducted simultaneously looking at either a one hour intravenous infusion every 28 days or a one hour infusion weekly for 4 weeks every 42 days [8-10]. Dose limiting toxicities included hypoglycemia and supraventricular tachycardias were seen with doses higher than $4000 \mathrm{mg} / \mathrm{m}^{2}$ given every 28 days. There were seven minor responses seen in patients with non-small cell lung cancer ( six) and colon cancer (one). Using a weekly schedule, the MTD was determined to be $2000 \mathrm{mg} / \mathrm{m}^{2} / \mathrm{wk}$ [8]. In this study there were a total of three minor responses in patients with non-small cell lung cancer (two) and colorectal cancer (one). In one study, it was shown that when correcting for protein binding, the equivalent target human plasma CQS concentration derived from the human tumor 
colony-forming assay would be at least $100 \mu \mathrm{g} / \mathrm{ml}$ during a minimum of $24 \mathrm{~h}$ [8].

Based on the evidence of preclinical antitumor activity and the presence of antitumor activity in colon cancer in both phase I studies, a phase II study of CQS in patients with metastatic colorectal cancer was conducted.

\section{Patient and methods}

\section{Patient selection}

Patients entered on this study had metastatic colorectal cancer and measurable disease. Patients were allowed up to one prior chemotherapy, and in addition could have one biologic therapy. Patients were also allowed to have had adjuvant therapy only if the recurrence was at least six months after receiving therapy. Additional inclusion criteria were ECOG performance status of $\leq 2$, normal organ and marrow function as defined by leukocytes of $>3,000 / \mathrm{ml}$, absolute neutrophil count of $>1,500 / \mathrm{ml}$ platelets $>100,000 / \mathrm{ml}$, total bilirubin within normal institutional limits, AST and/or ALT $<2.5 \mathrm{X}$ institutional upper limit of normal and creatinine within normal institutional limits.

\section{Treatment}

CQS was given using the schedule of $2000 \mathrm{mg} / \mathrm{m}^{2}$ over an hour weekly for 4 weeks every 42 days. Based on phase I data, patients on this study were carefully monitored for cardiac arrhythmias and disturbances in glucose metabolism. Patients had an ECG strip prior to and after their weekly treatment during the first cycle and then the first day of each subsequent cycle. In addition, blood glucose was checked prior to each treatment and then by fingerstick every $2 \mathrm{~h}$ post treatment for $4 \mathrm{~h}$ for the first cycle and for any episode clinically consistent with hypoglycemia.

\section{Efficacy assessment}

Patients were evaluated at baseline and every 12 weeks for response. Tumor measurements were done by CT scanning and responses were assessed using RECIST criteria [11].

\section{Safety assessment}

Toxicity was assessed using the NCI Common Toxicity Criteria (CTC) version 2.0

\section{Pharmacokinetic analysis}

We performed limited pharmacokinetics based on the results of the phase I studies [8-10]. Pharmacokinetic analysis was performed at 0,2 and $24 \mathrm{~h}$ following the first dose of CQS administration. Samples were obtained from
3 patients. Serum analysis of CQS levels was performed using the HPLC method previously described [3, 8]. Essentially, various amounts of CQS were added to $0.5 \mathrm{ml}$ of blank human plasma to result in concentrations ranging between 500 and $4000 \mathrm{ng} / \mathrm{ml}$ and R-XK469 \{(2-[4-(7Chloro-2-quinoxaliny) oxy] phenoxy propionic acid) $\}$ was used as the internal standard, to result in a concentration of $1 \mu \mathrm{g} / \mathrm{ml}$. These solutions were used to construct a calibration curve. For plasma samples $0.5 \mathrm{ml}$ was used with the concentration of internal standard used kept constant at $1 \mu \mathrm{g} / \mathrm{ml}$. Plasma proteins were precipitated by use of 2.5 $\mathrm{ml}$ of acetonitrile. After centrifugation at $1500 \mathrm{~g}$, the supernatant was removed and evaporated under a stream of nitrogen. The residue was reconstituted in $200 \mu \mathrm{l}$ of mobile phase and a $50 \mu \mathrm{l}$ aliquot was analyzed for CQS by HPLC. The mobile phase consisted of $30 \%$ methanol containing 20 $\mathrm{mM}$ ammonium nitrate and $0.2 \%$ acetic acid. The flow rate was $1 \mathrm{ml} / \mathrm{min}$ and the components were detected by UV at $330 \mathrm{~nm}$. HPLC was typically run for 30-40 min. Under the stated condition, the typical retention times were 20.8 min for R-XK469 and 24.15 min for CQS, with no other major peaks in the chromatogram up to 40 min elution time. No attempt was made to locate and identify CQS metabolites. The assay was linear from 0.5 to $4000 \mu \mathrm{g} / \mathrm{ml}$. of CQS using $0.5 \mathrm{ml}$ plasma. The within day reproducibility was evaluated at $0.5,1$ and $2 \mu \mathrm{g} / \mathrm{ml}$ concentrations with shown percent $\mathrm{CV}$ values of 3.9,5.5 and 9.2 respectively $(n=6)$. The corresponding accuracy percent values 96.3, 90.9 and 85.6 respectively.

\section{Statistical considerations}

This was a minimax two-stage design of Simon with the primary endpoint being overall response rate. In this design we considered CQS to be uninteresting or ineffective if the true response probability was less than $20 \%$. The twostage design establishes that if 3 or fewer responses are seen in the first 19 response-evaluable patients, the study is terminated early and CQS is deemed ineffective for this patient population.

\section{Results}

\section{Patient characteristics}

The majority of patients $(94 \%)$ had received prior chemotherapy (Table 1). The most commonly used regimens were 5FU and CPT-11. The rest of the characteristics are listed in Table 1.

\section{Objective response}

Sixteen patients were evaluable for response with fifteen patients showing evidence of disease progression and one patient with prolonged stable disease. One patient had non- 
Table 1. Patients characteristics

\begin{tabular}{lc}
\hline Gender & \\
Male & $59 \%(10 / 17)$ \\
Female & $41 \%(7 / 17)$ \\
Race & \\
White & $82 \%(14 / 17)$ \\
Black & $12 \%(2 / 17)$ \\
Asian & $6 \%(1 / 17)$ \\
Site of disease & \\
Colon & $65 \%(11 / 17)$ \\
Rectum & $35 \%(6 / 17)$ \\
Performance status & \\
0 & $59 \%(10 / 17)$ \\
1 & $35 \%(6 / 17)$ \\
2 & $6 \%(1 / 17)$ \\
Prior therapy & $94 \%(16 / 17)$ \\
Participating sites & \\
Cleveland Clinic & $8 / 17$ \\
Ohio State Univ & $3 / 17$ \\
University of MI & $3 / 17$ \\
Central Baptist & $3 / 17$ \\
\hline
\end{tabular}

evaluable disease. Following this interim analysis, the drug was considered ineffective and the study was terminated early.

\section{Safety}

Toxicities from this drug at the dose tested were very mild.. Most common toxicities included anemia (24\%), constipation (18\%), hypoglycemia, leukopenia, flushing, stomatitis, sensory neuropathy, headache and fatigue (12\%). Only 1 patient had grade 3 toxicity with urticaria. No patients had grade 4 toxicity on this study. For a full list of toxicities , please refer to Table 2.

\section{Pharmacokinetic analysis}

Three patients were studied and the results are shown in Figure 1. Essentially, serum CQS levels were consistently below the therapeutic target of $100 \mu \mathrm{g} / \mathrm{ml}$ in the first $24 \mathrm{~h}$ after the CQS dose administered.

\section{Discussion}

This phase II study of the novel compound Chloroquinoxaline Sulfonamide (CQS)-a halogenated derivative of sulfaquixonaline- in patients with advanced colorectal cancer was initiated based on promising in vitro and in vivo anticancer activity as well as some anticancer activity in a prior phase I study [8]. In this study we showed that CQS given at $2000 \mathrm{mg} / \mathrm{m}^{2}$ over an hour weekly for
Table 2. Observed toxicities with CQS

\begin{tabular}{|c|c|c|c|c|c|}
\hline \multirow[b]{2}{*}{ Toxicity } & \multicolumn{5}{|c|}{ Grade $\%(\mathrm{~N})$} \\
\hline & $\begin{array}{l}\text { All } \\
\text { grades }\end{array}$ & Grade 1 & Grade 2 & Grade 3 & Grade 4 \\
\hline Anemia & $24 \%(4)$ & $24 \%(4)$ & & & \\
\hline Constipation & $18 \%(3)$ & $18 \%(3)$ & & & \\
\hline Hypoglycemia & $12 \%(2)$ & & $12 \%(2)$ & & \\
\hline $\begin{array}{l}\text { Sensory } \\
\text { Neuropathy }\end{array}$ & $12 \%(2)$ & $12 \%(2)$ & & & \\
\hline Flushing & $12 \%(2)$ & $12 \%(2)$ & & & \\
\hline Stomatitis & $12 \%(2)$ & $12 \%(2)$ & & & \\
\hline Fatigue & $12 \%(2)$ & $6 \%(1)$ & $6 \%(1)$ & & \\
\hline Headache & $12 \%(2)$ & $12 \%(2)$ & & & \\
\hline Leucopenia & $12 \%(2)$ & & $12 \%(2)$ & & \\
\hline Lymphopenia & $6 \%(1)$ & $6 \%(1)$ & & & \\
\hline Urticaria & $6 \%(1)$ & & & $6 \%(1)$ & \\
\hline Nausea & $6 \%(1)$ & & $6 \%(1)$ & & \\
\hline Hyperglycemia & $6 \%(1)$ & $6 \%(1)$ & & & \\
\hline Ataxia & $6 \%(1)$ & & $6 \%(1)$ & & \\
\hline Fever & $6 \%(1)$ & $6 \%(1)$ & & & \\
\hline $\begin{array}{l}\text { Musculoskeletal } \\
\text { pain }\end{array}$ & $6 \%(1)$ & $6 \%(1)$ & & & \\
\hline $\begin{array}{l}\mathrm{VZV} \\
\quad \text { reactivation } *\end{array}$ & $6 \%(1)$ & & $6 \%(1)$ & & \\
\hline $\mathrm{DVT}^{\wedge}$ & $6 \%(1)$ & & $6 \%(1)$ & & \\
\hline
\end{tabular}

*Varicella zoster reactivation

${ }^{\dagger}$ Deep venous thromobosis

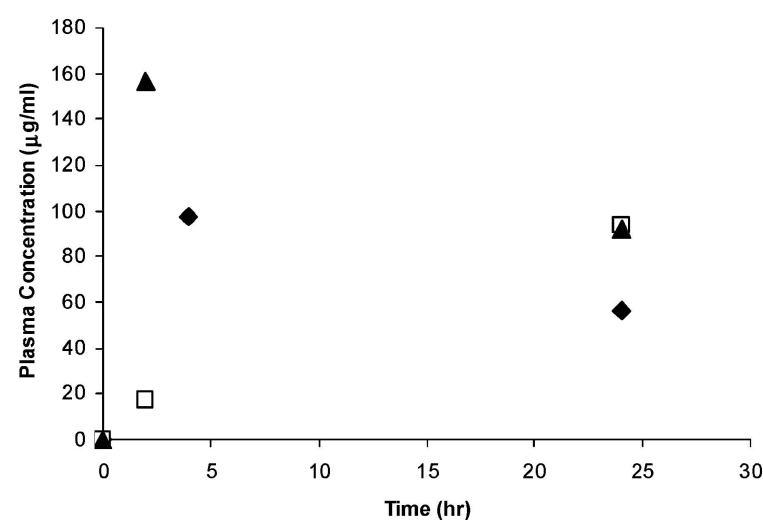

Figure 1. Pharmacokinetics of CQS at 0,2 and 24 hours after the administration of the first dose of CQS. The limited sampling was performed on only 3 patients.

4 weeks every 42 days was well tolerated but lacked clinical activity in patients with metastatic colorectal cancer.

The lack of efficacy in this study might possibly be related to one or more of the following: (1) All 3 patients included in the pharmacokinetic analysis failed to achieve the target serum level of $100 \mu \mathrm{g} / \mathrm{ml}$ in the first $24 \mathrm{~h}$. However, this was a limited pharmacokinetic analysis (as intended by the 
study design), and data from all patients were not available. However, a previously published study looking at CQS with the same dose/schedule in patients with non-small cell lung cancer showed no activity of the drug despite that the target concentration being achieved in $90 \%$ of the patients following dose readjustments in a number of those patients. (2) The fact that most patients had been exposed to prior therapy. It is well known that second line therapy in colorectal cancer is largely ineffective with response rates of less than $10 \%[12,13]$. Our study was designed to consider a response rate of at least $20 \%$ as interesting, approximately double the response rate seen with "active" therapies in the second-line setting $[12,13]$. Perhaps this response rate of interest was too ambitious, resulting in an underestimation of the activity of this drug. (3) As noted before, CQS inhibits both topo II $\alpha$ and II $\beta$ [5]. Published in vivo data suggests a good rationale for targeting topo II in colorectal cancer based on a higher level of expression of topo II $\alpha$ gene in tumors relative to normal tissue [14]. However, this study suggested that the sequential chemotherapy targeting topo I and topo II enzymes by modulating topo II $\alpha$ expression by topo I inhibitors might be more effective in colon cancer, in terms of their relationship between topo I and topo II $\alpha$ expression in tumor cells [14]. Perhaps, an improved strategy might be to use this drug is in sequence with a topo I inhibitor such as irinotecan, a drug with activity in colorectal cancer.

In conclusion, CQS given intravenously at $2000 \mathrm{mg} / \mathrm{m}^{2}$ over an hour weekly for 4 weeks every 42 days was well tolerated but lacked noticeable activity in patients with metastatic colorectal cancer. This lack of activity might be related to one on more element as noted above, however, further study of CQS at this dose and schedule cannot be recommended.

\section{Acknowledgment}

We would like to appreciatively acknowledge the funding for this study came in part from NCI Phase II Program grant number NCI U01-CA63185.

\section{References:}

1. Jemal A, Murray T, Ward E, Samuels A, Tiwari RC, Ghafoor A, Feuer EJ, Thun MJ: Cancer statistics, 2005. CA Cancer J Clin 55(1):10-30, 2005

2. Pazdur R., Coia LR, Wagman LD, Ayoub JP: Colorectal and Anal Cancers. In: Cancer Management: A Mulitidisciplinary Approach.
Third Edition. Ed. By Pazdur R, Coia L, Hoskins WJ,Wagman LD. PRRR, Huntington NY, 1999

3. Tong WP, Hartshorn J, Mathews LA: Chloroquinoxaline sulfonamide, investigational drug brochure. National Cancer Institute, Division of Cancer treatment, 1987

4. Branda RF, McCormack JJ, Perlmutter CA: Cellular pharmacology of chloroquinoxaline sulfonamide and a related compound in murine B16 melanoma cells. Biochem Pharmacol. 37(23):4557-4564, 1988

5. Gao H, Yamasaki EF, Chan KK, Shen LL, Snapka RM: Chloroquinoxaline sulfonamide (NSC 339004) is a topoisomerase $\mathrm{IIa} / \beta$ poision. Cancer Res 60: 5937-5940, 2000

6. Hickey R, Schiffer J, Wei Y, Malkas L: DNA synthesis is differentially affectd by the drugs mebarone and chloroquinoxaline. Proc Am Assoc Cancer Res 34:352, 1993

7. Branda RF, Moore AL, McCormack JJ: Immunosuppressive properties of chloroquinoxaline sulfonamide. Biochem Pharmacol 38: 3521-3526, 1989

8. Rigas JR, Tong WP, Kris MG, Orazem JP, Young CW, Warrell RP Jr: Phase I clinical and pharmacological study of chloroquinoxaline sulfonamide. Cancer Res 52(23):6619-6623, 1992

9. Conley BA, O’Hara S, Wu S, Melink TJ, Parnes H, Pardoe E, Egorin MJ, Van Echo DA: Phase I trial of chloroguinoxaline sulfonamide, with correlation of its pharmacokinetics and pharmacodynamics. Cancer Chemother Pharmacol 37(1-2):139-149, 1995

10. Rigas JR, Francis PA, Miller VA, Tong WP, Roistacher N, Kris MG, Orazem JP, Young CW, Warrell RP Jr: Clinical and pharmacology study of chloroquinoxaline sulfonamide given on a weekly schedule. Cancer Chemother Pharmacol 35(6):483-488, 1995

11. Therasse P, Arbuck SG, Eisenhauer EA, Wanders J, Kaplan RS, Rubinstein L, Verweij J, Van Glabbeke M, van Oosterom AT, Christian MC, Gwyther SG: New guidelines to evaluate the response to treatment in solid tumors. European Organization for Research and Treatment of Cancer, National Cancer Institute of the United States, National Cancer Institute of Canada. J Natl Cancer Inst. 92(3):205-216, 2000

12. Rothenberg ML, Oza AM, Bigelow RH, Berlin JD, Marshall JL, Ramanathan RK, Hart LL, Gupta S, Garay CA, Burger BG, Le Bail N, Haller DG: Superiority of oxaliplatin and fluorouracilleucovorin compared with either therapy alone in patients with progressive colorectal cancer after irinotecan and fluorouracilleucovorin: interim results of a phase III Trial. JCO 2059-2069, 2003

13. Tournigand C, Andre T, Achille E, Lledo G, Flesh M, Mery-Mignard D, Quinaux E, Couteau C, Buyse M, Ganem G, Landi B, Colin P, Louvet C, de Gramont A: FOLFIRI followed by FOLFOX6 or the reverse sequence in advanced colorectal cancer: a randomized GERCOR study. J Clin Oncol 22(2):229-237, 2004

14. Kim R, Ohi Y, Inoue $\mathrm{H}$, Toge $\mathrm{T}$ : Expression and relationship between topoisomerase I and II alpha genes in tumor and normal tissues in esophageal, gastric and colon cancers. Anticancer Res. 19(6B):5393-5398, 1999

Address for offprints: Tanios S. Bekaii-Saab, The Ohio State University, B 421 Starling Loving Hall, 320 W 10th Avenue, Columbus, OH, 43210. E-mail: saab-1@medctr.osu.edu 